\title{
PROGESTERONE VERSUS RITODRINE IN MANAGEMENT OF PRETERM LABOR
}

\author{
By \\ Mohammed A. El-Sayed, Mofeed F. Mohammed and Ahmed M. El- \\ Sadek \\ Department of Obstetrics and Gynecology, Faculty of Medicine, Al-Azhar University, \\ Cairo, Egypt \\ *Corresponding Author: Mohammed Ali El-Sayed, E-mail: aboalimenady@ gmail.com
}

\begin{abstract}
Background: Preterm labor (PTL) and delivery remain a significant problem in contemporary obstetric practice. Although the exact cause remains unclear, it is most likely to be multifactorial in nature. Progesterone may be effective in prevention of premature birth in some high risk populations. Women with arrested premature labor are at risk of recurrent labor and maintenance therapy with standard tocolytics has not been successful.
\end{abstract}

Objective: To compare the efficacy and safety of beta-sympathomimetics (Ritodrine) and Progesterone for maintenance tocolysis after arrested preterm labor for prolongation of pregnancy and prevention of recurrence of preterm labor.

Subjects and methods: This study was a case-control study which was carried out to evaluate the efficacy and safety of beta-sympathomimetics (Ritodrine) and Progesterone for maintenance tocolysis after arrested preterm labor. This study was carried out on 100 pregnant women attending Sohag Teaching Hospital and Al-Azhar University Hospital (Al-Hussein) in gestational age between 28 and 37 weeks, from August 2019 to August 2020. Patients were divided into two equal groups: Group (A) received oral ritodrine (yutopar), and Group (B) received progesterone vaginal suppository (prontogest 400).

Results: Among participants in Group A, there were $41(82 \%)$ multigravida and $9(18 \%)$ primigravida, while in Group B there were $45(90 \%)$ multigravida and $5(10 \%)$ primigravida. The mean maternal age in Group A was $25.52( \pm 3.94 \mathrm{SD})$ with range (19-32), while the mean maternal age in Group B was $26.64( \pm 3.84 \mathrm{SD})$ with range (21-32). There were 27 (54\%) in Group A who had Previous PTL or abortion while there were 21 $(42 \%)$ in Group B only. There was a high statistically significant difference between the studied groups as regard outcome babies.

Conclusion: Progesterone has the upper hand on ritodrine in maintenance tocolysis. Also, it showed that neonatal outcomes were better with progesterone and the maternal side effects were fewer with progesterone than ritodrine.

Keywords: Preterm labor, Tocolysis, Ritodrine, Progesterone.

\section{INTRODUCTION}

Despite advances in perinatal medicine, the incidence of preterm birth continues to increase. The primary goal of tocolytic therapy is to reduce neonatal morbidity and mortality. While studies have demonstrated prolongation of pregnancy, no tocolytic drug has been shown to improve neonatal outcomes (Simhan et al., 2018).

Preterm birth (PTB) is currently the leading cause of childhood mortality in children under 5 years (Harrison and Goldenberg, 2015). In 2010, 14.9 million 
babies were born preterm, accounting for $11.1 \%$ of all births worldwide. Rates of PTB range from approximately 5\% of births in European countries, to $18 \%$ in certain African countries (Blencowe et al., 2012).

Much of the economic burden can be attributed to neonatal intensive care, often followed by ongoing health care and educational requirements, in addition to the emotional impact experienced by families (Howson et al., 2013).

Preterm labor (PTL) can be initiated by multiple mechanisms, including infection or inflammation, uteroplacental ischemia or hemorrhage, uterine over distension or stress (Goldenberg et al., 2010).

Maternal risk factors include extremes in maternal age, body mass index (BMI), multiple gestations, the use of assisted reproductive technologies, history of PTB and low socioeconomic status (Rubens et al., 2014).

In general, tocolytic therapies are largely ineffective at substantially delaying delivery and reducing neonatal mortality (Haas et al., 2012).

The most commonly used tocolytic agents are beta-adrenergic agonists. Metaanalysis has shown that beta-adrenergic agonists, especially ritodrine are associated with a postponement of delivery 24, 48 hours and 7 days. However such a delay has not been associated with a significant reduction in either perinatal mortality or morbidity. The great incidence of usually mild but potentially severe side effects of betasympathomimetics has led to the search for better drugs. Progesterone is useful in allowing pregnancy to reach term (Elovitz et al., 2011).

Several trials have reported the benefits of vaginal progesterone administration for reducing the rates of PTB and improving neonatal outcome. However, these studies had limited information on the long term outcome of these infants (Dodd et al., 2013).

The aim of this study was to compare the efficacy and safety of betasympathomimetics (Ritodrine) and Progesterone for maintenance tocolysis after arrested preterm labor for prolongation of pregnancy and prevention of recurrence of preterm labor.

\section{PATIENTS AND METHODS}

This was a case-control study carried out to evaluate the efficacy and safety of beta-sympathomimetics (Ritodrine) and Progesterone for maintenance tocolysis after arrested preterm labor. This study was carried out to pregnant women attending Sohag Teaching Hospital and Al-Azhar University Hospital (AlHussein) in gestational age between 28 and 37 weeks, from August 2019 to August 2020.

Group A: received oral Ritodrine $10 \mathrm{mg}$ tablet was given every 12 hours till 37 weeks of pregnancy or till deliver whichever occurred early.

A total of 100 pregnant women was included in the study and divided into two equal groups:

Group B: received progesterone pessaries containing $400 \mathrm{mg}$ natural progesterone per pessary. It was used by the patient as one pessary per vaginum at bed-time until 
37 weeks or till delivery whichever occurred early.

All regimens of administration started after stoppage of acute attack of preterm labor whatever the method of management.

Inclusion criteria: History of painful regular uterine contractions associated with boats of diarrhea or associated with menstrual like cramps, singleton pregnancy, intact membranes, the dating of pregnancy confirmed through first ultrasound scanning or last menstrual period and cervical dilation of $3 \mathrm{~cm}$ or less.

Exclusion criteria: Acute attack of preterm labor, cervical dilation $>3 \mathrm{~cm}$, hypotension (less than $80 \mathrm{mmHg}$ systolic or $50 \mathrm{mmHg}$ diastolic), major fetal congenital anomalies, unreassuring traces of fetal cardiotocography, ante-partum hemorrhage or history of recurrent vaginal bleeding, rupture of membranes, multiple pregnancy, polyhydraminos, chorioamnionitis, unexplained pyrexia, medical disorders, i.e. diabetes, cardiac disease, sensitivity or contraindications to ritodrine and other tocolytic therapy during this pregnancy.

\section{All patients were subjected to:}

1. Informed written consent.

2. History taking: Personal history, present history, obstetric history, menstrual history, past history and family history.

3. General examination: With special attention to blood pressure, pulse and temperature, Blood pressure for all the patients should be above 100/60 mmHg before commencement of treatment.
4. Abdominal examination: To palpate the uterine contractions and monitoring of the fetal heart rate.

5. Sonographic assessment: To estimate the gestational age, amount of liquor and exclude placenta previa, placental abruption and major fetal congenital anomalies. Several ultrasound parameters will be used to estimate gestational age including biparietal diameter (BPD), head circumference (HC), and femur length (FL).

6. Pelvic examination: To assess the state of membranes and exclude their rupture through examination with a sterile Cusco speculum, to exclude vaginal bleeding and assess the state of the cervix.

7. Urine analysis: To detect urinary tract infection.

8. Administration of tocolytic agent in the form of vaginal progesterone, or oral ritodrine. If the women were stable and undelivered after $48 \mathrm{~h}$ of maintenance tocolysis, they would be discharged and followed-up in the antenatal care clinic.

All patients were discharged with the following instructions: - Avoid intercourse, heavy work and carrying heavy things. - Return back to the hospital if developed symptoms of preterm labor. - At every visit, fetal growth was assessed clinically and patients were evaluated for side-effects. - Maintenance tocolysis was given until 37 weeks or to the onset of spontaneous labour, whichever occurred earlier.

9. Follow up of the patient weekly in the obstetric outpatient clinic until delivery 
to detect the date and mode of delivery and the outcome.

\section{Statistical analysis:}

Data were fed to the computer and analyzed using IBM SPSS software package version 20.0. (Armonk, NY: IBM Corp) Qualitative data were described using number and percent. The Kolmogorov-Smirnov test was used to verify the normality of distribution Quantitative data were described using range (minimum and maximum), mean, standard deviation, median and interquartile range (IQR). Significance of the obtained results was judged at the $5 \%$ level. Chi-square test was used for categorical variables, to compare between different groups. Fisher's exact correction for chi-square was used when more than $20 \%$ of the cells have expected count less than 5. Student t-test was used for normally distributed quantitative variables, to compare between two studied groups. Mann Whitney test was used for abnormally distributed quantitative variables, to compare between two studied groups. A $p$ value of $\leq 0.05$ was considered statistically significant for all analyses.

\section{RESULTS}

Among participants in Group A, there were $41(82 \%)$ multigravida and $9(18 \%)$ primigravida, while in Group B there were 45 (90\%) multigravida and 5 (10\%) primigravida. The mean maternal age in Group A was $25.52( \pm 3.94 \mathrm{SD})$ with range (19-32) while the mean maternal age in Group B was $26.64( \pm 3.84 \mathrm{SD})$ with range
(21-32). There were 27 (54\%) in Group A who had Previous PTL or abortion while there were $21(42 \%)$ in Group B only. There was no statistically significant difference between the studied groups as regard Parity, Maternal age or Previous PTL or abortion (Table 1).

Table (1): Comparison between the two studied groups according to obstetric history

\begin{tabular}{|c|c|c|c|c|c|}
\hline \multirow{2}{*}{ Obstetric history } & \multicolumn{2}{|c|}{$\begin{array}{c}\text { Group A } \\
(\mathbf{n}=\mathbf{5 0})\end{array}$} & \multicolumn{2}{|c|}{$\begin{array}{c}\text { Group B } \\
(\mathbf{n}=\mathbf{5 0})\end{array}$} & \multirow[t]{2}{*}{$\mathbf{p}$} \\
\hline & No. & $\%$ & No. & $\%$ & \\
\hline \multicolumn{6}{|l|}{ Parity } \\
\hline MG. & 41 & 82.0 & 45 & 90.0 & \multirow[t]{2}{*}{0.249} \\
\hline PG. & 9 & 18.0 & 5 & 10.0 & \\
\hline \multicolumn{6}{|l|}{ Maternal Age (years) } \\
\hline Min. - Max. & \multicolumn{2}{|c|}{$19.0-32.0$} & \multicolumn{2}{|c|}{$21.0-32.0$} & \multirow[t]{3}{*}{0.153} \\
\hline Mean \pm SD. & \multicolumn{2}{|c|}{$25.52 \pm 3.94$} & \multicolumn{2}{|c|}{$26.64 \pm 3.84$} & \\
\hline Median (IQR) & \multicolumn{2}{|c|}{$26.0(21.0-29.0)$} & \multicolumn{2}{|c|}{$26.0(23.0-30.0)$} & \\
\hline \multicolumn{6}{|l|}{ Previous PTL or abortion } \\
\hline No & 23 & 46.0 & 29 & 58.0 & \multirow[t]{2}{*}{0.230} \\
\hline Yes & 27 & 54.0 & 21 & 42.0 & \\
\hline
\end{tabular}

$\chi 2$ : Chi square test, $t$ : Student t-test.

$\mathrm{p}$ : $\mathrm{p}$ value for comparing between the studied groups.

Group A: Oral ritodrine (yutopar).

Group B: Progesterone vaginal suppository (prontogest 400). 
Among participants in Group A, there were $8(16 \%)$ have asymptomatic bactiuria in urine analysis (U.A) while there were 7 (14\%) in Group B. The mean frequency of recurrence of cases in Group A was $2.45( \pm 1.12 \mathrm{SD})$ with range $(0.7$ 4.2 ), while the mean frequency of recurrence in Group B was $1.96( \pm 0.61$ $\mathrm{SD})$ with range (0.8-3). The mean Gestational age at delivery of cases in Group A was $34.74( \pm 3.02$ SD) with range (28-38), while the mean gestational age at delivery in Group B was $36.2( \pm 2.53$ SD) with range (28-38). The mean tocolysis duration of cases in Group A was 1.27 $( \pm 0.51$ SD) with range $(0.48-2.29)$ while the mean tocolysis duration in Group B was $4.29( \pm 2.62 \mathrm{SD})$ with range (0.78.61). There was a statistically significant difference between the studied groups as regards tocolysis duration. There was a statistically significant difference as regards frequency of recurrence, and gestational age at delivery and there was no statistically significant difference as regard U.A (Table 2).

Table (2): Comparison between the two studied groups according to different parameters

\begin{tabular}{|c|c|c|c|c|c|}
\hline \multirow{2}{*}{ Parameters } & \multicolumn{2}{|c|}{$\begin{array}{c}\text { Group A } \\
(n=50)\end{array}$} & \multicolumn{2}{|c|}{$\begin{array}{c}\text { Group B } \\
(\mathbf{n}=\mathbf{5 0})\end{array}$} & \multirow{2}{*}{$\mathbf{p}$} \\
\hline & No. & $\%$ & No. & $\%$ & \\
\hline \multicolumn{6}{|l|}{$\begin{array}{l}\text { U.A (Asymptomatic } \\
\text { bactiuria). }\end{array}$} \\
\hline No & 42 & 84.0 & 43 & 86.0 & \multirow{2}{*}{0.779} \\
\hline Yes & 8 & 16.0 & 7 & 14.0 & \\
\hline \multicolumn{6}{|l|}{ Frequency of recurrence } \\
\hline Min. - Max. & \multicolumn{2}{|c|}{$0.70-4.20$} & \multicolumn{2}{|c|}{$0.80-3.0$} & \multirow{3}{*}{$0.008^{*}$} \\
\hline Mean \pm SD. & \multicolumn{2}{|c|}{$2.45 \pm 1.12$} & \multicolumn{2}{|c|}{$1.96 \pm 0.61$} & \\
\hline Median (IQR) & \multicolumn{2}{|c|}{$2.45(1.50-3.40)$} & \multicolumn{2}{|c|}{$1.95(1.60-2.50)$} & \\
\hline \multicolumn{6}{|l|}{$\begin{array}{l}\text { Gestational age at delivery } \\
\text { (weeks) }\end{array}$} \\
\hline Min. - Max. & \multicolumn{2}{|c|}{$28.0-38.0$} & \multicolumn{2}{|c|}{$28.0-38.0$} & \multirow{3}{*}{$0.010^{*}$} \\
\hline Mean \pm SD. & \multicolumn{2}{|c|}{$34.74 \pm 3.02$} & \multicolumn{2}{|c|}{$36.20 \pm 2.53$} & \\
\hline Median (IQR) & \multicolumn{2}{|c|}{$36.0(33.0-37.0)$} & \multicolumn{2}{|c|}{$37.0(36.0-38.0)$} & \\
\hline \multicolumn{6}{|l|}{ Tocolysis duration } \\
\hline Min. - Max. & \multicolumn{2}{|c|}{$0.48-2.29$} & \multicolumn{2}{|c|}{$0.71-8.61$} & \multirow{3}{*}{$<0.001^{*}$} \\
\hline Mean \pm SD. & \multicolumn{2}{|c|}{$1.27 \pm 0.51$} & \multicolumn{2}{|c|}{$4.29 \pm 2.62$} & \\
\hline Median (IQR) & \multicolumn{2}{|c|}{$1.17(0.85-1.75)$} & \multicolumn{2}{|c|}{$4.55(1.69-6.75)$} & \\
\hline
\end{tabular}

$\chi 2$ : Chi square test, t: Student t-test, U: Mann Whitney test.

$\mathrm{p}$ : $\mathrm{p}$ value for comparing between the studied groups.

*: Statistically significant at $\mathrm{p} \leq 0.05$.

Group A: Oral ritodrine (yutopar).

Group B: Progesterone vaginal suppository (prontogest 400).

Among the babies delivered in Group A, there were $20 \quad(40 \%)$ entered Incubation, 14 (28\%) discharged, and 16 (32\%) end. Among the babies delivered in Group B, there were 12 (24\%) entered
Incubation, $35(70 \%)$ discharged, and 3 (6\%) end. There was a statistically significant difference between the studied groups as regards outcome babies (Table 3). 
Table (3): Comparison between the two studied groups according to outcome

\begin{tabular}{|l|c|c|c|c|c|}
\hline \multirow{2}{*}{ Groups } & \multicolumn{2}{|c|}{$\begin{array}{c}\text { Group A } \\
(\mathbf{n = 5 0 )}\end{array}$} & \multicolumn{2}{c|}{$\begin{array}{c}\text { Group B } \\
(\mathbf{n = 5 0})\end{array}$} & \multirow{2}{*}{$\mathbf{p}$} \\
\cline { 2 - 5 } & No. & \% & No. & \% & \\
\hline Incubation & 20 & 40.0 & 12 & 24.0 & \multirow{2}{*}{$<0.001^{*}$} \\
\hline Discharged & 14 & 28.0 & 35 & 70.0 & \\
\hline END & 16 & 32.0 & 3 & 6.0 & \\
\hline
\end{tabular}

$\chi 2$ : Chi square test.

$\mathrm{p}: \mathrm{p}$ value for comparing between the studied groups.

*: Statistically significant at $\mathrm{p} \leq 0.05$.

Group A: Oral ritodrine (yutopar).

Group B: Progesterone vaginal suppository (prontogest 400).

Among the cases of Group A, there were 13 (26\%) had hypotension, 7 (14\%) had palpitation, 9 (18\%) had tachycardia, $6(12 \%)$ had flushing and redness and 50 (100\%) had atonic postpartum hemorrhage $(\mathrm{PPH})$. Among the cases of Group B, there were 2 (4\%) had hypotension, $5(10 \%)$ had palpitation, 4 (8\%) had tachycardia, 2 (4\%) had nausea and vomiting, and $50(100 \%)$ had atonic post-partum hemorrhage (PPH). There was a statistically significant difference between the studied groups as regard hypotension and flushing and redness, while there was no statistically significant difference as regards palpitation, tachycardia, nausea and vomiting and atonic PPH (Table 4).

Table (4): Comparison between the two studied groups according to maternal side effects and complications

\begin{tabular}{|l|c|c|c|c|c|}
\hline \multirow{2}{*}{$\begin{array}{l}\text { Maternal side } \\
\text { Groups }\end{array}$} & \multicolumn{2}{c|}{$\begin{array}{c}\text { Group A } \\
(\mathbf{n = 5 0}\end{array}$} & \multicolumn{2}{c|}{$\begin{array}{c}\text { Group B } \\
(\mathbf{n = 5 0})\end{array}$} & \multirow{2}{*}{ p } \\
\cline { 2 - 5 } & No. & \% & No. & $\%$ & \\
\hline Hypotension & 13 & 26.0 & 2 & 4.0 & $0.002^{*}$ \\
\hline Palpitation & 7 & 14.0 & 5 & 10.0 & 0.538 \\
\hline Tachycardia & 9 & 18.0 & 4 & 8.0 & 0.137 \\
\hline Nausea \& vomiting & 0 & 0.0 & 2 & 4.0 & ${ }^{\mathrm{FE}} \mathrm{p}=0.153$ \\
\hline Flushing and redness & 6 & 12.0 & 0 & 0.0 & ${ }^{\mathrm{FE}} \mathrm{p}=0.012^{*}$ \\
\hline Constipation & 0 & 0.0 & 0 & 0.0 & - \\
\hline Atonic PPH & 50 & 100.0 & 50 & 100.0 & - \\
\hline
\end{tabular}

$\chi 2$ : Chi square test, FE: Fisher Exact.

$\mathrm{p}$ : $\mathrm{p}$ value for comparing between the studied groups.

*: Statistically significant at $\mathrm{p} \leq 0.05$.

Group A: Oral ritodrine (yutopar).

Group B: Progesterone vaginal suppository (prontogest 400).

\section{DISCUSSION}

In Group A there were $82 \%$ multigravida and $18 \%$ primigravida, while in Group B there were $90 \%$ multigravidas and $10 \%$ primigravida. The mean maternal age in Group A was 25.52 ( $\pm 3.94 \mathrm{SD})$ with range (19-32) while the mean maternal age in Group B was 26.64 $( \pm 3.84 \mathrm{SD})$ with range (21-32). There were $54 \%$ in Group A had previous PTL or abortion, while there were $42 \%$ in Group B only. There was no statistically significant difference between the studied 
groups as regard parity, maternal age or previous PTL or abortion.

In the study of Mohie-Eldin et al. (2017), they concluded that when comparing patient characteristics in the tow study groups there was no statistically significant difference between study groups as regards the age, parity, gestational age at admission and number of previous preterm labor. Also, there is no statistically significant difference in $\mathrm{Hb}$ level and presence of asymptomatic bacteruria in between patients included in the study groups with a special noting that anemic patients in this study were associated with urinary tract infection which is consistent with our results as regard the aforementioned parameters.

In the study of Khalid et al. (2019), there was no significant difference in terms of mean age, maternal history, BMI, HB level, and history of PTL.

The early detection of pregnant women at high risk for preterm delivery could be the best way to prevent preterm birth. In the present study, 100 eligible pregnant women with a gestational age between 28 weeks and 37 weeks were included, out of which for maintenance tocolysis, 50 received oral ritodrine, 50 women received progesterone pessaries.

In our study, in Group A there were $16 \%$ with asymptomatic bactiuria in U.A, while there were $14 \%$ in Group B. There was a statistically significant difference between the studied groups as regards tocolysis duration, frequency of recurrence and gestational age at delivery, and there was no statistically significant difference as regards U.A.
Mohie-Eldin et al. (2017) concluded that there was a statistically significant difference between the study groups with higher percentage of recurrence in ritodrine group (80\%) if compared with and progesterone group (40\%). There was a statistically significant difference between both groups as regards tocolysis duration and median gestational age.

Freak-Poli et al. (2011) reported that incidence of delivery before 34 weeks of gestation was $19.2 \%$ in progesterone group compared with $34.4 \%$ in placebo group and the difference was statistically significant. Uterine contractions were more frequently found among placebo group than in the progesterone group (54.3\% Vs $23.6 \%)$ respectively. As regard the mean gestational age at delivery, there was a statistically significant difference between the three study groups with higher mean in progesterone group if compared to ritodrine group but there is no significant difference compared to ritodrine group. As regard prolongation of gestation to 37 weeks or more, there was a statistically significant difference between the study groups with more prolongation of gestational age in progesterone group $(60 \%)$ if compared to ritodrine group $(23.3 \%)$.

However, these results were not in agreement with the results reported by O'Brien et al. (2010) who reported that progesterone did not decrease the frequency of preterm birth rates $(<32$ weeks of gestation). As regards frequency of recurrence of attacks of preterm labour there was a statistically significant difference between the study groups with higher mean of recurrence in ritodrine 
group $(2.5 \pm 1.13)$ if compared to both and progesterone group.

On the other hand, study was done by Papatsonis et al. (2012) to compare the efficacy with ritodrine in the management of preterm labor, Regarding tocolysis duration, our results came in accordance with the randomized, multi-centric trial done by Van De Water et al. (2010).

Comparison between the two studied groups according to outcome, the babies delivered in Group A were $40 \%$ entered Incubation, 28\% discharged, and 32\% end. Among the babies delivered in Group B there were $24 \%$ entered Incubation, $70 \%$ discharged, and $3(6 \%)$ end.

In the study of Mohie-Eldin et al. (2017), the neonatal outcome in the studied group of patients the babies delivered in Group A (ritodrine group) were $40 \%$ entered Incubation, 30\% discharged, and $30 \%$ end. Among the babies delivered in Group B there were $33.3 \%$ entered Incubation, $60 \%$ discharged, and $6.7 \%$ end. They concluded that, there was no statistically significant difference between the two study groups, but there was a statistically significant difference between progesterone group if compared to ritodrine group as $60 \%$ of babies discharged together with the mother to the home, $33.3 \%$ of babies were incubated and $6.7 \%$ of babies develop early neonatal death. However, in ritodrine group, 30\% of babies were taken to the home, $40 \%$ were incubated, and $30 \%$ of babies develop early neonatal death which comes in correlation with our results.

Papatsonis et al. (2012) supported the previous work on ritodrine for treatment of preterm labor with respect to neonatal outcome. There were no significant differences in umbilical artery $\mathrm{pH}$ values and Apgar scores between groups. Progesterone was associated with lower admission rates to the NICU (49\% versus $66 \%$ ) compared with ritodrine, and lower incidences of $\operatorname{RDS}(21 \%$ versus $37 \%)$, intracranial bleeding (18\% versus $31 \%$ ), and neonatal jaundice (52\% versus $67 \%$ ) which is consistent with our results.

There was a statistically significant difference between the studied groups as regard hypotension and flushing and redness while there was no statistically significant difference as regard Palpitation, tachycardia, nausea and vomiting and atonic PPH.

Mohie-Eldin et al. (2017) concluded that difference between the two study groups as regards maternal side effects as tachycardia and palpitation were more common in patients receiving ritodrine than in other patient groups, while flushing and redness were more common in retodrine group $(16.6 \%)$ than progesterone groups $(10 \%)$ but without significant difference between the two groups. Also there was a higher incidence of hypotension in ritodrine group. However, no women in our study discontinued medication due to adverse effects or medication intolerance. As regards, maternal postpartum complications, atonic postpartum hemorrhage was the main complication of tocolysis, but there was no statistically significant difference between the two study groups on incidence of postpartum hemorrhage which consistent with our study. 


\section{CONCLUSION}

There was overall difference between progesterone, and ritodrine in their efficacy as maintenance tocolysis for prevention of recurrence of preterm labor. Progesterone has the upper hand on ritodrine in maintenance tocolysis. Neonatal outcomes were better with progesterone, and the maternal side effects were fewer with progesterone than ritodrine.

\section{REFERENCES}

1. Blencowe H, Cousens S, Oestergaard MZ, Chou D, Moller AB, Narwal R, Adler A, Vera Garcia C, Rohde S Say L and Lawn JE. (2012): National, regional,and worldwide estimates of preterm birth rates in the year 2010 with timetrends since 1990 for selected countries: a systematic analysis andimplications. Lancet, 379: 2162-2172.

2. Dodd JM, Jones L, Flenady V, Cincotta $R$ and Crowther CA. (2013): Prenatal administration of progesterone for preventing preterm birth in women considered to be at risk of preterm birth. Cochrane Database Syst Rev., 7: 4947-52.

3. Elovitz MA, Brown AG, Breen K, Anton L, Maubert $M$ and Burd I. (2011): Intrauterine inflammation, insufficient to induce parturition, still evokes fetaland neonatal brain injury. Int J Dev Neurosci., 29: 663-671.

4. Freak-Poli R, Chan A, Tucker $G$ and Street J. (2011): Previous abortion and risk of pre-term birth: a population study. J Matern Fetal Neonatal Med., 22: 1-7.

5. Goldenberg RL, Culhane JF and Iams JD. (2010): Preterm birth 1: epidemiology and causes of preterm birth. Lancet, 371:75-79.

6. Haas DM, Caldwell DM, Kirkpatrick P, Mcintosh JJ and Welton NJ. (2012): Tocolytic therapy for preterm delivery: systematic review and networkmeta-analysis. BMJ, 345: 6226-32.
7. Harrison MS and Goldenberg RL. (2016): Global burden of prematurity. Semin Fetal Neonatal Med., 21(2):74-9.

8. Howson CP, Kinney MV, Mcdougall $L$ and Lawn JE. (2013): Born too soon: pretermbirth matters. Reprod. Health, 10 (1): $1-5$.

9. Khalid A, Khan AM, Anwar A, Yousaf M, Anwar $O$ and Parveen A. (2019): Comparison between glyceryl trinitrate and ritodrine as a tocolytic agent in pre-term labour. APMC, 13(1):1-3.

10. Mohie-Eldin A, Mohammaed HF and Abdel-Ghany AM. (2017): Comparative study between progesterone and Ritodrine for maintenance tocolysis in management of preterm labour. Clin Obstet Gyneco Reprod Med., 3(5):1-5.

11. O'Brien JM, Barto JR and Milligan DA. (2010): An aggressive interventional protocol for early midtrimester premature rupture of the membranes using gelatin sponge for cervical plugging. Am J Obstet Gynecol., 187: 1143-48.

12. Papatsonis D, Flenady $\mathrm{V}$ and Liley $\mathrm{H}$. (2012): Maintenance therapy with oxytocin antagonists for inhibiting preterm birth after threatened preterm labour. Cochrane Database Syst Rev., 11: 16-22.

13. Rubens CE, Sadovsky Y, Muglia L, Gravett MG, Lackritz $\mathbf{E}$ and Gravett $C$. (2014): Prevention of preterm birth: harnessing science to address the global epidemic. Sci Trans Med., 6: 262-5.

14. Simhan HN, Iams JD and Romero R. (2018): Preterm labor and birth. Gabbe's Obstetrics Essentials: Normal \& Problem Pregnancies E-Book, Pp. 203.

15. Van De Water M, Kessel ET, De Kleine MJ and Oei SG. (2010): Tocolytic effectiveness of nifedipine versus ritodrine and follow-up of newborns: a randomised controlled trial. Acta Obstet Gynecol Scand., 87: 340-345. 
مقارنة بين استخدام عقار البروجستيرون و عقار الريتودرين

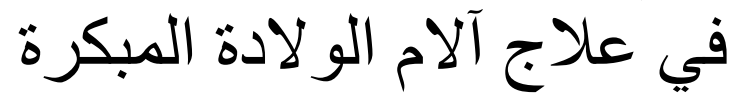

محمد على السيد أحمد, مفيد فوزي محمد, أحمد محمد الصادق لاد الحرة قسم أمر اض النساء والتوليد، كلية طب، جامعة الأزهر بالقاهرة، مصر

E-mail: aboalimenady@gmail.com

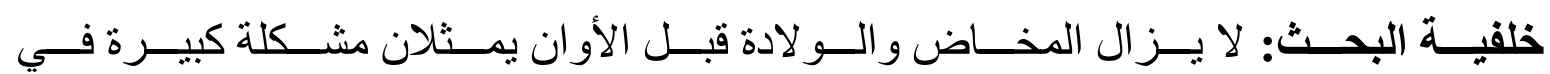

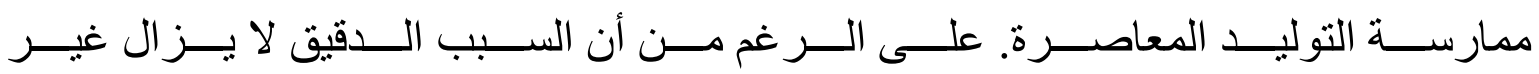

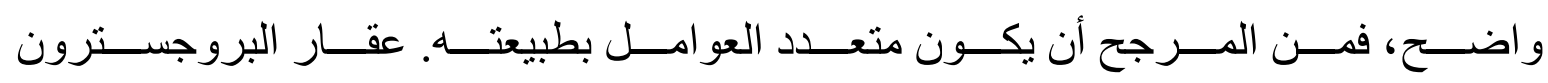

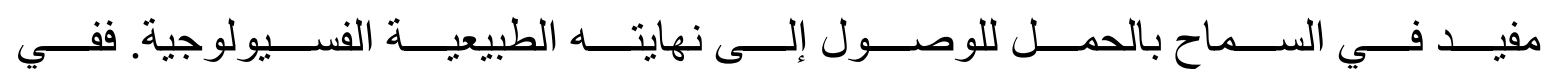

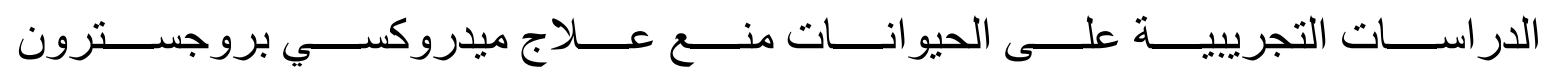

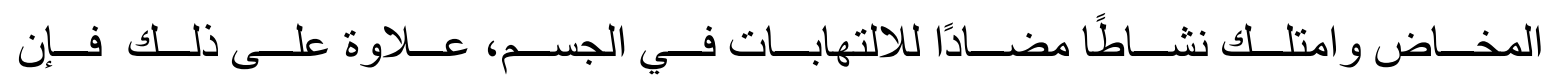

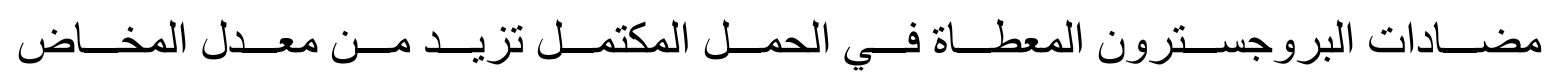

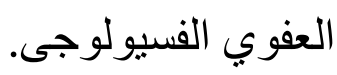

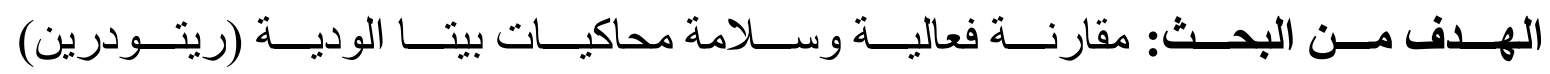

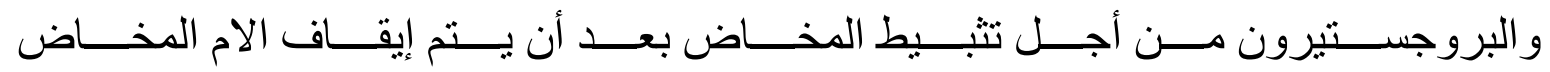

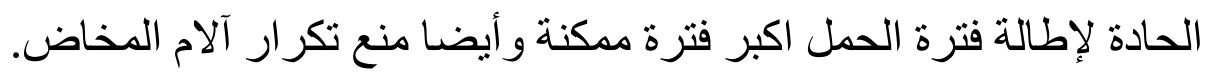

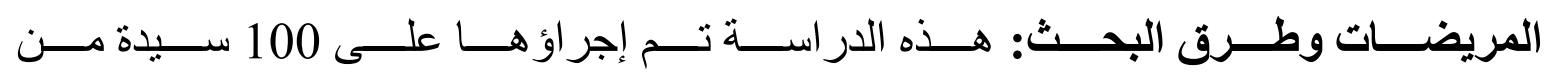

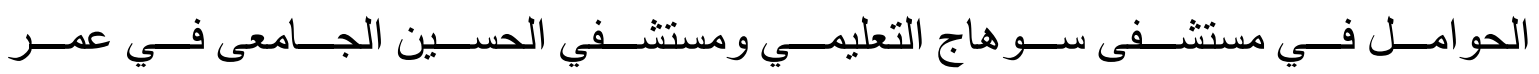

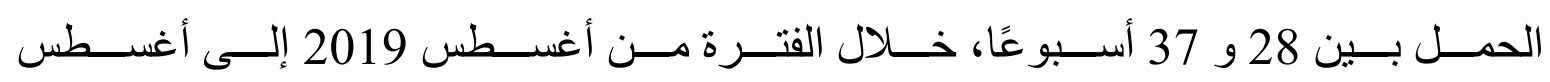

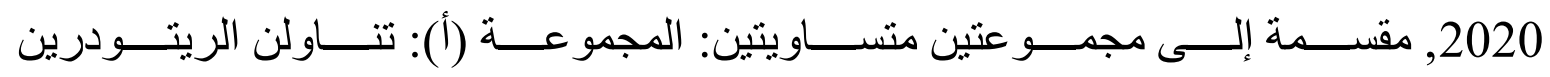

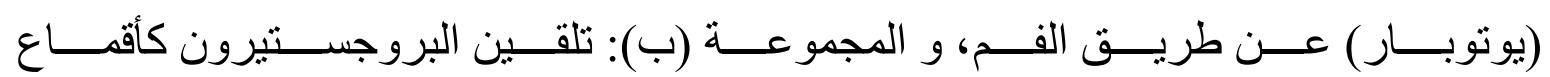

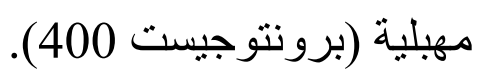

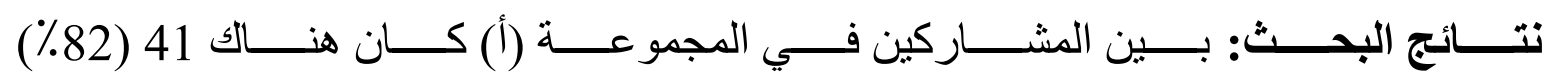

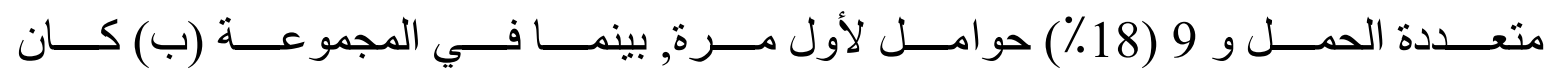




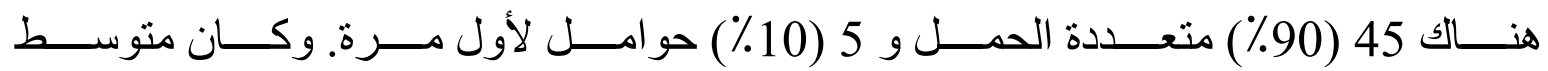

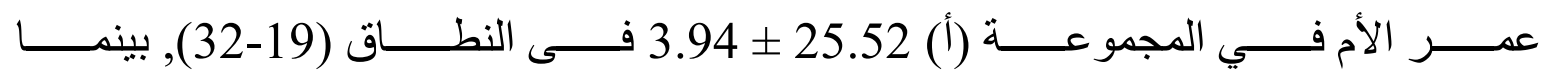

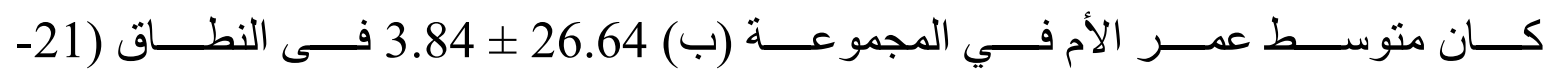

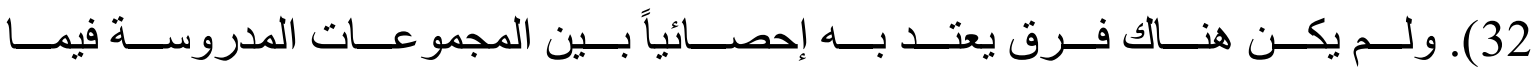

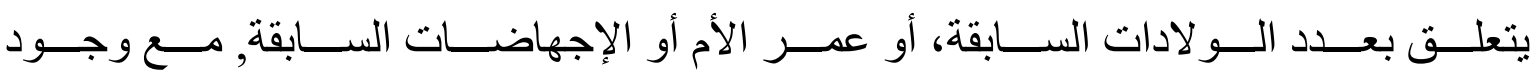

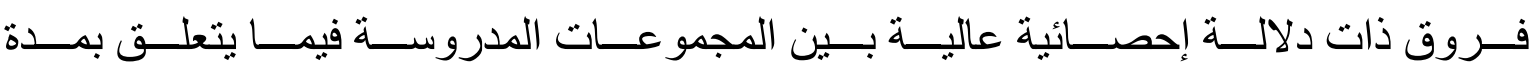

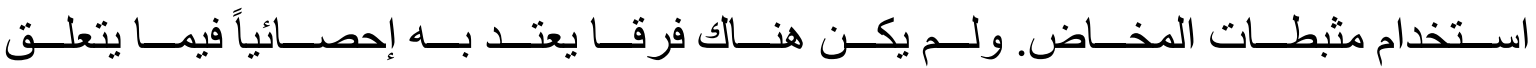

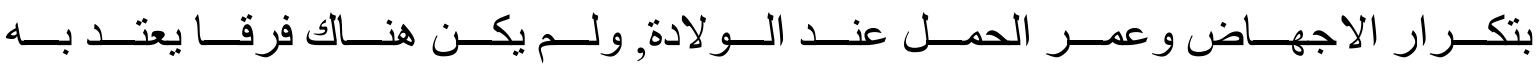
إحصائياً فيما ينعلق بوجود الإنهابات فى مجرى البول.

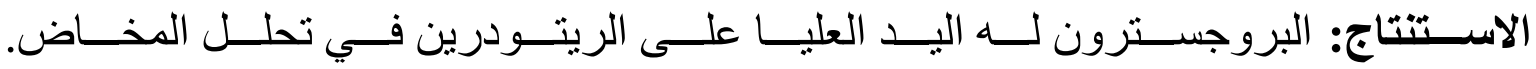

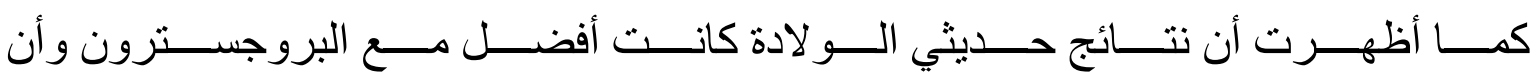
الآثار الجانبية للام كانت أقل مع البروجسترون من الريتودرين.

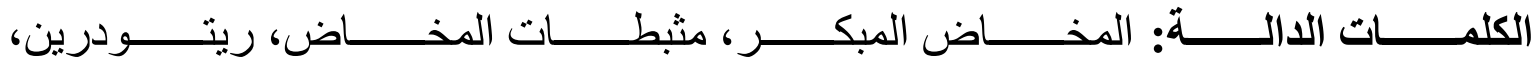

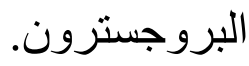

